\title{
Metastatic Renal Cell Carcinoma of the Thyroid
}

\author{
Joanna Sanchez ${ }^{\mathrm{a}}$, Manoj Kumar ${ }^{\mathrm{a}, \mathrm{b}}$
}

\begin{abstract}
Metastatic tumors to the thyroid gland are rare. We report a case of metastatic renal cell carcinoma of the thyroid gland detected 15 years after radical nephrectomy for the primary tumor. Clinical and histopathological aspects of this unusual case are discussed. The possibility of an intra-thyroidal metastasis should be considered when evaluating a thyroid nodule.
\end{abstract}

Keywords: Metastasis; Renal cell carcinoma; Thyroid; Nephrectomy

\section{Introduction}

Metastasis of renal cell carcinoma (RCC) to the thyroid is very rare. The most common sources of metastases to the thyroid are kidney, skin, breast and lung. Clear cell carcinoma is the most common histologic type of RCC. In one-third of cases, the metastasis occurs many years after diagnosing the primary RCC. The most common manifestation of thyroid metastasis is an enlarged thyroid gland or a palpable neck mass.

\section{Case Report}

A 53-year-old female presented to the ENT outpatient department with a history of sensation of something in her neck for almost 6 months. Examination revealed evidence of a $2 \mathrm{~cm}$ nodule in the right thyroid lobe. This was confirmed by an ultrasound scan. She subsequently underwent fine needle aspiration cytology which showed suspicious cells but was not diagnostic. A right hemi-thyroidectomy was therefore carried out. Frozen section also failed to give a definitive diagnosis. The histopathological examination showed metastatic RCC of clear

Manuscript accepted for publication January 14, 2014

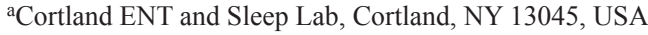

${ }^{b}$ Corresponding Author: Manoj Kumar, Cortland ENT and Sleep Lab, Cortland, NY 13045, USA. Email: mkumar@cortlandent.com

doi: http://dx.doi.org/10.14740/jmc1466w cell type (Fig. 1). Immunohistochemical staining showed CD10 positivity (Fig. 2) in the RCC areas and thyroglobulin positivity (Fig. 3) in the normal thyroid tissue areas of the specimen.

The patient gives history of RCC on the right side almost 15 years ago. At that time she had undergone right radical nephrectomy. The histology at that time showed clear cell RCC. She was followed up by the nephrologists for almost 10 years and no evidence of recurrence noted. Tumor was not infiltrating through the capsule. Surgical margins and bladder cuff were free of tumor. TNM staging was that of T2N0M0.

\section{Discussion}

Incidence of RCC has been rising in the last few decades and accounts for $3 \%$ of adult malignancies [1]. RCC is the most common malignant epithelial tumor of the kidney, accounting for $85-90 \%$ of all solid renal tumors in adults [2]. In almost half of the patients with RCC, metastasis was noted at the time of presentation [3]. There are three major types of RCC. These are papillary, clear cell and chromophobe. Clear cell carcino$\mathrm{ma}$ is the most common type accounting for $75 \%$ of all RCCs. Clear cell RCC has an unfavorable diagnosis compared to the other subtypes [4]. It is documented that recurrence and distant metastasis may occur many years following radical nephrecto-

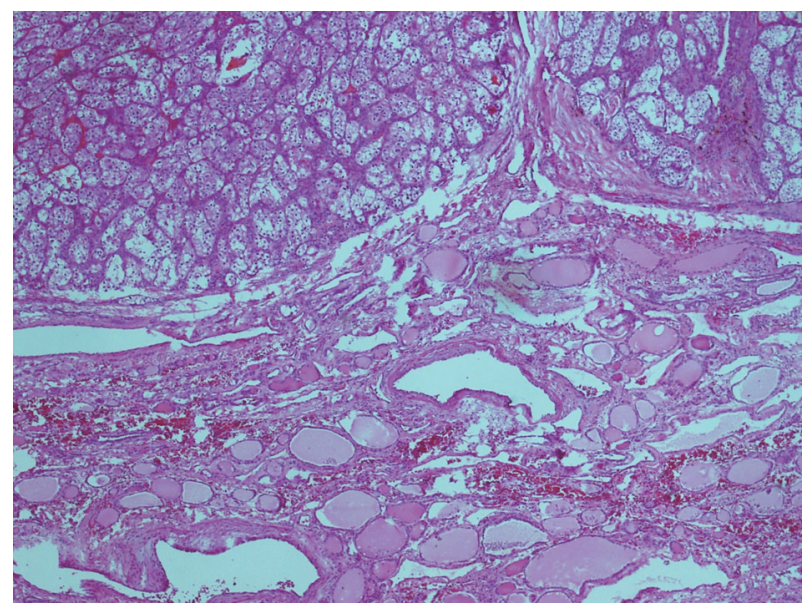

Figure 1. This slide shows both RCC and adjacent benign thyroid tissue. Small arrow shows renal cell cancer. 


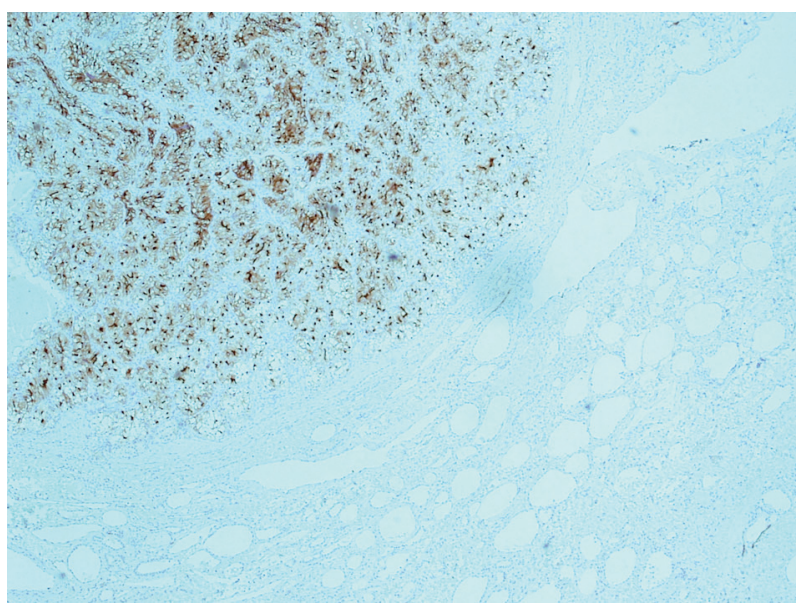

Figure 2. Immunohistochemical stain CD10 shows positive staining in the RCC area of the thyroidectomy specimen.

my for RCC. Such a late occurrence of metastasis necessitates the need for long-term follow-up of these patients [5].

Metastatic tumors in the thyroid gland are rare compared to primary tumors [6]. The spread of non-thyroid malignancies in the thyroid has been reported in $1.4-3 \%$ of patients with thyroid malignancies undergoing thyroid surgery [7]. The thyroid gland is among the most vascularized organs in the body and hence is vulnerable to metastatic disease [3]. The most common sources of metastases to the thyroid include kidney, skin, breast, and lung, and head and neck, but more than $50 \%$ of the time the source is RCC in clinically recognized metastasis to the thyroid $[8,9]$.

RCC of the thyroid has been documented in the past. Based on autopsy findings, Chung et al detected thyroid metastasis from RCC in 5\% of the cases [10]. A 20-year retrospective review of surgical pathology and autopsy pathology database for patients with metastatic carcinoma to the thyroid identified a total of 10 patients with metastatic carcinoma to the thyroid; six were in surgical pathology specimens out of a total of 1,295 thyroid carcinomas $(0.46 \%)$ and four were diagnosed at autopsy out of a total of 2,117 $(0.19 \%)$ autopsy cases during this period [11]. The primary tumor was RCC only in one of these 10 cases.

Metastatic deposits in the thyroid may be asymptomatic or present with few symptoms. The usual symptoms of metastatic RCC to the thyroid gland are enlarged solitary or multiple neck swellings, painless palpable thyroid nodules, shortness of breath, vocal changes, wheezing and difficulty in swallowing, but most secondary metastases of the thyroid are asymptomatic. However, because both RCC and clear cell thyroid follicular tumors contain clear cytoplasmic characteristics, using fine needle aspiration cytology alone creates an increased chance of misdiagnosis [9].

Fine needle aspiration cytology is a useful diagnostic test in detecting renal cell metastasis in thyroid. However, when FNA findings are inconclusive, hemi- or total thyroidectomy needs to be done to confirm the diagnosis. Immunocytochemistry and electron microscopy are also useful tools to make the distinction between primary and metastatic tumors. RCC has a

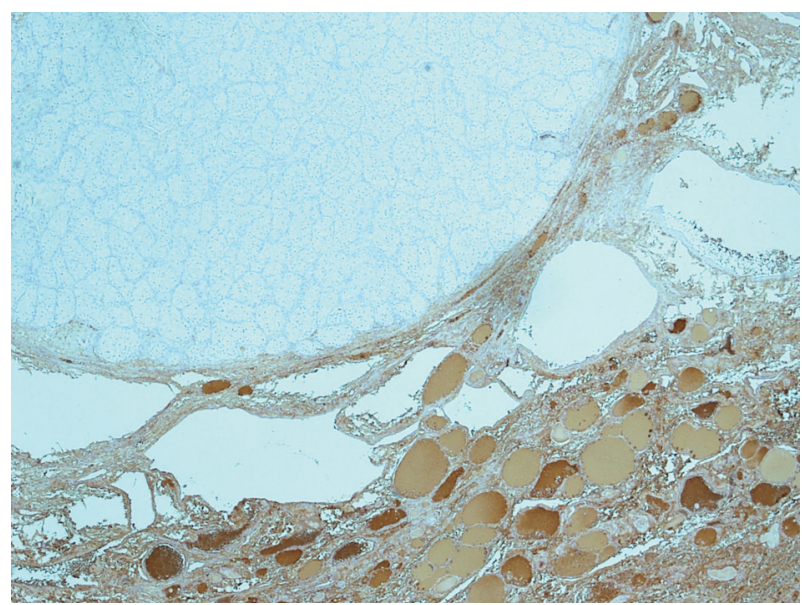

Figure 3. Immunohistochemical stain thyroglobulin shows positive staining in the thyroid gland and negative staining in the area infiltrated with RCC.

slow growth rate with low glucose metabolism, and therefore the PET scan may fail to detect the cancer [1]. Thyroid nodule in any patient with a past history of renal cell malignancy should be considered as potentially metastatic.

\section{References}

1. Zamarron C, Abdulkader I, Areses MC, Garcia-Paz V, Leon L, Cameselle-Teijeiro J. Metastases of renal cell carcinoma to the thyroid gland with synchronous benign and malignant follicular cell-derived neoplasms. Case Rep Oncol Med. 2013;2013:485025.

2. Gurel S, Narra V, Elsayes KM, Siegel CL, Chen ZE, Brown JJ. Subtypes of renal cell carcinoma: MRI and pathological features. Diagn Interv Radiol. 2013;19(4):304-311.

3. Riaz K, Tunio MA, Alasiri M, Elbagir Mohammad AA, Fareed MM. Renal cell carcinoma metastatic to thyroid gland, presenting like anaplastic carcinoma of thyroid. Case Rep Urol. 2013;2013:651081.

4. Cheville JC, Lohse CM, Zincke H, Weaver AL, Blute ML. Comparisons of outcome and prognostic features among histologic subtypes of renal cell carcinoma. Am J Surg Pathol. 2003;27(5):612-624.

5. Kuruvath S, Naidu S, Bhattacharyya M, Benjamin JC, O'Donovan DG. Spinal metastasis from renal cell carcinoma, 31 years following nephrectomy--case report. Clin Neuropathol. 2007;26(4):176-179.

6. Papi G, Fadda G, Corsello SM, Corrado S, Rossi ED, Radighieri E, Miraglia A, et al. Metastases to the thyroid gland: prevalence, clinicopathological aspects and prognosis: a 10-year experience. Clin Endocrinol (Oxf). 2007;66(4):565-571.

7. D'Angelo FA, Magistri P, Antolino L, Socciarelli F. Granulomatous reaction within the thyroid metastases of a renal cell carcinoma. Int J Surg Pathol. 2014;22(1):87-89.

8. Hegerova L, Griebeler ML, Reynolds JP, Henry MR, Gharib H. Metastasis to the Thyroid Gland: Report of a 
Large Series From the Mayo Clinic. Am J Clin Oncol. 2013.

9. Duggal NM, Horattas MC. Metastatic renal cell carcinoma to the thyroid gland. Endocr Pract. 2008;14(8):10401046.

10. Chung AY, Tran TB, Brumund KT, Weisman RA, Bouvet
M. Metastases to the thyroid: a review of the literature from the last decade. Thyroid. 2012;22(3):258-268.

11. Moghaddam PA, Cornejo KM, Khan A. Metastatic carcinoma to the thyroid gland: a single institution 20-year experience and review of the literature. Endocr Pathol. 2013;24(3):116-124. 